\title{
Partnership between patients and health care professionals is an important determinant of patient satisfaction
}

\author{
Michael Heberer ${ }^{1}$, Linda Bourke ${ }^{1}$, Frances Wildhaber ${ }^{* 1}$, Josef Sütterlin ${ }^{2}$ \\ ${ }^{1}$ Institute of Surgical Research and Hospital Management, University Hospital of Basel, Switzerland \\ ${ }^{2}$ MECON measure \& consult GmbH, Badenerstrasse 281, Zürich, Switzerland
}

Received: November 4, 2015

DOI: $10.5430 /$ ijh.v2n1p90
Accepted: December 1, 2015 Online Published: December 14, 2015

URL: http://dx.doi.org/10.5430/ijh.v2n1p90

\begin{abstract}
Background: A five year single institution survey of patient experience was analysed according to organisational units and for disease- and treatment- based patient groups to detect potential predictors of patient satisfaction.

Methods: The public and academic, acute care hospital was monitored during times of change in reimbursement and ownership (2010-2014) and exhibited a high level of overall patient satisfaction (score 3.5/4) which remained constant over the duration of the study. Out of 134,593 in-house patients during this period, 54,686 responded (40.6\%) to the 18-question survey mailed a fortnight after hospital discharge. This patient satisfaction database was merged with the medical and administrative database in order to enable subgroup analysis and factorial analysis performed.

Results: Despite a high level of overall patient satisfaction there existed remarkable heterogeneity within the hospital in patient satisfaction between different organisational units or patient groups. Patient socio-demographic factors remained stable among the groups and over time and made a significant but albeit small, contribution to patient satisfaction variance: organisational units $(0.7 \%)$, age $(0.22 \%)$, patient origin $(0.12 \%)$, gender $(0.1 \%)$, type of insurance $(0.04 \%)$, migration status $(0.03 \%)$ and destination (post-discharge location, $0.02 \%$ ). Without a significant influence was comorbidity, admission status, or length of stay. Using factorial analysis the single most relevant factor was partnership which explained $25 \%$ of the variance of patient satisfaction. Partnership or "partnership between patients and health care professionals" included coherent information exchange, involvement in decision-making and treatment with dignity and respect. Other components influencing satisfaction were responsiveness, information, family involvement and pain control (accounting for 1\%-8\% variance).

Conclusions: The structural heterogeneity of hospitals demands the analysis of patient satisfaction in subgroups and over periods of time (trend analysis). Furthermore, "partnership between patients and the health care professionals" appears to be a factor that offers potential for quality improvement initiatives.
\end{abstract}

Key Words: Patient-centred care, Patient satisfaction, Service quality, Shared decision-making

\section{INTRODUCTION}

Complication rates and mortality have traditionally been used to assess the quality of medical care. More recently patient-reported measures, such as patient satisfaction have emerged and are increasingly used to monitor and guide quality improvement efforts ${ }^{[1]}$ in the United States (US) ${ }^{[2]}$ and

\footnotetext{
*Correspondence: Frances Wildhaber; Email: frances.wildhaber@usb.ch; Address: Institute of Surgical Research and Hospital Management, University Hospital of Basel, Spitalstrasse 21, CH-4031 Basel, Switzerland.
} 
Europe $^{[3]}$ with evidence of success ${ }^{[4]}$ and improved outcome through better continuity of care and compliance. ${ }^{[5,6]}$

The shift to increased patient involvement has witnessed a migration from paternalistic approaches where clinicians dominate and decide, ${ }^{[7]}$ to more active patients with clinician partnership, exchanging information, detailling preferences and deciding on options together, ${ }^{[8]}$ or shared decision-making. ${ }^{[9]}$

Whilst this so-called "patient revolution" ${ }^{[10]}$ is most prominent in the US, European equivalents start to emerge, with England introducing mandatory surveys of hospital inpatients annually since 2002 and Association Nationale de Qualite (ANQ) in Switzerland monitoring patient satisfaction since 2009.

Comparative studies of patient satisfaction, safety and quality across Europe and US exhibit significant variations between countries, with Switzerland (the location of this study) showing one of the highest patient outcome ratings, top hospital recommendations and high patient satisfaction with nurses, despite a mid-range ratio of patients to staff. ${ }^{[11]}$ Nevertheless there remains significant room for improvement.

Patient satisfaction is an accepted and important measure of health care quality that seems to be at least in part independent of other medical outcome measures ${ }^{[12]}$ and that fulfills the criteria of "a right to health indicator" ${ }^{[13]}$ Hospitals are complex organisations, where professional hierarchies of physicians, nursing, technical staff (including housekeeping and administrators) interact with patients. This staff is furthermore divided into the medical disciplines (e.g. surgery, internal medicine, psychiatry), which also have developed diverse cultures. ${ }^{[14]}$ It is therefore surprising that most reports on patient experience and satisfaction are published on a per-hospital basis rather than broken down into smaller and possibly more relevant, units of observation and management. Some authors, however, have realised the diversity of cultures and structures within a hospital organisation and proposed to study wards as the unit of analysis instead of the entire hospital, ${ }^{[15]}$ which is particularly relevant in those wards exhibiting considerable autonomy.

Here we analyse satisfaction per patient group (e.g. myocardial infarction, breast cancer) and consider this information important for patients and referring physicians. We also compare patient satisfaction across the wards (organisational units) and the clinical services (e.g. gastrointestinal surgery, gastroenterology) with the aim to advance the internal management of the relationship between patients and health care professionals. We furthermore test the results of specified patient segments (private treatment versus general insurance, migrant versus local population, young versus

Published by Sciedu Press old etc.) to analyse and improve medical services for target patient groups of the hospital. The flexibility of this analysis is based on the fusion and the concurrent anonymisation of datasets pertaining to patient satisfaction, medical information and administrative data.

We have developed, validated and implemented a continuous survey of patient satisfaction using a questionnaire that is sent out to all hospital inpatients after their discharge. Data were accumulated over five years (2010-2014).

This large, single institution, database is used (1) to challenge the hypothesis that subunits of the hospital (organisational units, patient groups) display significant heterogeneity with regard to patient satisfaction and (2) to identify determinants of patient satisfaction and their relative impact.

In particular, the following questions were asked:

(1) Is patient satisfaction related to general patient characteristics (such as age, gender, origin, migration status and insurance), disease-related items (such as disease group, comorbidities, length of stay), or hospital organisation (admission status, organisational units, destination)?

(2) Do the trends of satisfaction within these groups differ?

(3) Are there common denominators for patient satisfaction across these groups and at all points in time and what is their relative impact?

(4) Can conclusions regarding the management of patient satisfaction be derived?

\section{MeTHODS}

All patients discharged from the University Hospital Basel (UHB) between July 2010 and December 2014, received an 18-item questionnaire assessing their healthcare experience. The survey covered standard care (staff:patient ratio 1:6) and excluded the more highly staffed intensive care and intermediate care units. The questionnaire assessing quality of care, attitudinal loyalty and overall satisfaction has been described previously. ${ }^{[16]}$ It was sent out two weeks after patient discharge from hospital; the patients completed it at home and returned it to the UHB. 54,686 patients (out of 134,593) returned the questionnaire (40.6\%) typically within a week of receipt. There was no follow-up of the non-responders (shown in a pilot study that the outcome was unaffected), nor any comparison of the responder/non-responder patient profiles. The survey was initiated in the second half of 2010; data for the entire year is available for 2011-2014. The patient participation ranges from $36 \%$ to $48 \%$ depending on the year and the annual number of responses range from 6,835 (half year 2010) to 12,657. 
The questionnaire was derived from an abbreviated form of the Picker questionnaire. ${ }^{[3]}$ It focusses on the interaction between patients and health care professionals and was modified in a process of forward and backward translations from German to English, Italian, Spanish, French and the Turkish language. The generation of the questionnaire and the validation process was part of the initiative to create a short and basic Swiss national questionnaire (in use since 2012, ANQ) and has been summarised before. ${ }^{[16,17]}$

Two questions in the 18 item questionnaire ask the patient about their overall satisfaction with the hospital. Out of the remaining 16 questions 15 related to a subjective perception of the quality of care, such as treatment with dignity, comprehensability and availability of information etc. (see Table 1). One question, (Q10, did you experience pain?) was a filter question and was not used to monitor satisfaction.

The answering scale of the 15 reporting questions has three default possible answers worded according to the question (e.g. for question 1) When you had important questions to ask a nurse, did you get answers you could understand? The default answers are either 3 = Yes, always; 2 = Yes, sometimes; or $1=$ No (for more details see Table 1). This analysis relies on a combination of both subjective (patient satisfaction database) and objective data (medical and administrative database).

\subsection{Patient satisfaction}

For the purpose of this analysis, patient satisfaction was defined as the mean response to two questions: (1) How do you rate the quality of treatment received? (The possible answers being 4 = Excellent; 3 = Good; 2 = Fair; or 1 = Poor) and (2) Would you choose our hospital again for the same treatment? (With the alternative response of $4=$ Yes, of course; $3=$ Yes, I think so; 2 = No, I don't think so; or $1=$ Of course not.)

Results of the two questions were significantly correlated (Pearson correlation $=0.578, p<.000)$ and the mean of the two ratings subsequently referred to as patient satisfaction. The suitability of the scale used for the two questions comprising the patient satisfaction score, was confirmed by reliability analysis of the entire sample (Cronbach's alpha = 0.731 , item scale correlation $=0.578$ ) as well as with samples derived from individual years (Cronbach alpha between 0.724 and 0.741 , adjusted item-scale-correlation between 0.571 and 0.591 ). According to Bortz ${ }^{[18]}$ a good test should provide a Cronbach alpha of at least 0.8 . Values between 0.7 and 0.8 are acceptable particularly when taking into account the small number of items $(n=2)$ used to assemble the patient satisfaction score. The patient satisfaction score was calculated for every patient.

\subsection{Medical and administrative database}

The medical and administrative records of the hospital provided background objective patient data which were pooled with the subjective questionnaire responses prior to anonymisation of the combined dataset.

The socio-demographic data included in this dataset were:

(1) Patient origin (whether the patient lived in Basel [town and agglomeration], elsewhere in Switzerland, or in another country)

(2) Migration status (whether the individual is an immigrant or indigenous to Switzerland)

(3) Age (patient age in years at the time of hospital entry [rounded down to the last birthday])

(4) Gender (male/female)

(5) Admission status (emergency admission: whether hospital entry was elective, or on an emergency basis)

(6) Type of insurance (whether the patient was privately insured, semi-private or held general insurance)

(7) Organisational unit (in which ward the patient was treated prior to their discharge)

(8) Destination (after hospital discharge whether the patient relocated to another institution [such as old peoples home], to rehabilitation, or to their home)

(9) Comorbidity (Charlson index: number of simultaneous diseases experienced by the patient during hospital stay)

(10) Length of stay (duration of hospital stay either short term [1-4 days] or $>4$ days)

(11) Patient groups (assignment of patients to a number of major disease categories [non-exclusive])

The questionnaire database was case-wise merged with the corresponding medical and administrative information. The new dataset was anonymised as approved by the data security officer of the Kanton Basel-Stadt, Switzerland, and then subjected to analysis using SPSS (version 22.0).

\subsection{Descriptive analysis}

The average patient satisfaction was calculated for disease groups defined according to the Swiss Federal government (Swiss Inpatient Quality Indicators, 2013) in order to create disease-related patient groups. The other dimensions for patient grouping included organisational units of the hospital (wards), admission status (emergency vs. elective), insurance status (private, semi-private, basic coverage) and social status (local, immigrant). The average patient satisfaction was calculated for each of these groups as well as the mean for each term (half year) and over the entire period of the study (2010-2014).

The average means and the standard deviations were cal-

ISSN 2377-7338 E-ISSN 2377-7346 
culated in SPSS. Confidence intervals were calculated in tion over time were graphically prepared in EXCEL for the EXCEL and funnel plots derived. Trends of patient satisfac- socio-demographic factors listed above.

Table 1. English version of the full questionnaire

1. When you had important questions to ask a nurse, did you get answers you could understand?
- Yes, always
- Yes, sometimes
- I didn't have questions

2. When you had important questions to ask a doctor, did you get answers you could understand?
- Yes, completely
- Yes, somewhat
- I didn't have questions

3. Sometimes in the hospital, one doctor or nurse will say one thing and another will say something quite different. Did it happen to you?
- Yes, often
- Yes, sometimes
- No

4. If you had any anxieties or fears about your condition or treatment, did a doctor discuss them with you?
- Yes, completely
- Yes, somewhat
- I didn't have anxieties nor fears

5. Did the doctors talk in front of you as if you weren't there?
- Yes, often
- Yes, sometimes

6. Did you have enough to say about your treatment?
- Yes, definitely
- Yes, somewhat

- No

7. Did you feel like you were treated with respect and dignity while you were in the hospital?
- Yes, always
- Yes, sometimes

- No

8. If you had any anxieties or fears regarding your condition or treatment, did a nurse discuss them with you?
- Yes, completely
- Yes, somewhat
- I didn't have anxieties nor fears

- No

9. Was it easy for you to find someone on the hospital staff to talk to regarding your concerns?
- Yes, definitely
- Yes, somewhat
- I didn't want to talk about concerns

10. Were you ever in any pain?
- Yes, definitely
- No

11. Do you think that the hospital staff did everything they could to help control pain?
- Yes, sure
- Yes, somewhat

- No

12. Did your family, or someone close to you, have enough opportunity to talk to your doctor?
- Yes, definitely
- Yes, somewhat
- There were no family members or friends involved
- No
- The family didn't want, or need, to talk

13. Did the doctors and nurses give your family, or someone close to you, all the information they needed to help you recover?
- Yes, definitely
- Yes, somewhat
- There were no family members or friends involved
- No
- The family didn't want or need information

14. Did someone on the hospital staff explain the purpose of the medicine you were to take at home in a way you could understand?
- Yes, definitely
- Yes, somewhat
- I needed no explanation
- No
- I had no medications to take home

15. Did someone tell you about the medication side effects to watch out for after you went home?
- Yes, completely
- Yes, somewhat
- I needed no explanation
- No
- I had no medicines to take home

16. Were you informed about possible danger signals for your illness, or from operation, which you should watch out for at home?
- Yes, completely
- Yes, somewhat

- No

17. How do you rate the quality of treatment you were given in general?

$\begin{array}{ll}\text { - Excellent } & \bullet \text { Good } \\ \text { - Fair } & \bullet \text { Poor }\end{array}$

18. Would you come to our hospital again to treat the same disease/give birth?
- Yes, of course
- Yes, I think so
- No, I don't think so
- Of course not 


\subsection{Factorial analysis}

An exploratory factor analysis was performed in order to check the dimensionality of the measuring instrument of the 15 reporting questions. For this, at a minimum, interval scalebased data are needed ${ }^{[19]}$ and a normal distribution of values The ability to differentiate the rating scale is not derived primarily from the number of set answers. ${ }^{[18]}$ All questions were dichotomised to reduce skewness and curtosis in order to approach a normal distribution. Missing values were listwise deleted, whereby 471 cases were removed leaving a database of $n=54,215$ cases in total.

For the explorative factor analysis a principle component analysis, followed by Varimax rotation, was selected. The principal component analysis is particularly suitable for explorative investigations for extracting factors. Varimax rotation was used to enumerate and name the dimensions behind the 15 questions. ${ }^{[19]}$ The Kaiser-Meyer-Olkin measure of sampling adequacy was 0.781 and thereby confirmed that the underlying correlations matrix was suitable for a factor analysis. ${ }^{[19]}$ The Bartlett-test of sphericity is highly significant (chi-square $=135,205.987, \mathrm{df}=105, p<.000)$, therefore the basic overall data is seen to correlate.

In order to compute the components in the downstream analyses, the factor scores were estimated using linear regression and every response deposited in the dataset.

\subsection{Analysis of variance}

Variance analysis was used to explore the independent factors associated with patient satisfaction as dependent variable for the entire study population, as well as for subgroups and over time. Independent factors consisted of defined wards (organisational units), clinical services and several factual criteria used to describe the patients such as sex, age, insurance status and locality, and are nominally scaled leading to an analysis of variance as the method of choice to evaluate the effects of independent on dependent variables. The five components resulting from the factorial analysis (such as "partnership") were included as covariates in the analysis of variance.

\section{Results}

\subsection{Response rate}

The questionnaire response rate was $40.6 \%$ which is in line with previous studies. ${ }^{[17,20,21]}$ The number of respondents per organisational unit varied from $11 \%$ up to $52 \%$. A significantly higher response rate was observed from elective patients $(46 \%)$ compared to emergency patients (35\%). Further, patients transferring permanently to another institution responded less often $(25 \%)$ than those returning home $(45 \%)$ or going to rehabilitation $(40 \%)$.

\subsection{Statistical analysis}

High satisfaction was seen with a hospital overall scoring of 3.53 (ceiling at 4), this is a well-known phenomenon of patient satisfaction surveys in Switzerland. ${ }^{[11]}$

The average patient satisfaction (during 2010-2014) of every organisational unit was plotted against the numbers of the prevailing respondents and the case-dependent confidence interval included (funnel plot, see Figure 1). This representation enabled the identification of outliers and confirmed heterogeneity between units within the hospital over the entire period 2010-2014. Funnel plots prove useful for a longitudinal trend analysis of in- and outliers.

Patient satisfaction at the level of the entire hospital, remained constant over time, irrespective of the organisational and economic changes that occurred in its' environment (see Figure 2, panel a) such as the introduction of diagnosisrelated group reimbursement in 2012 and funding independence in 2013; when this hospital, the UHB migrated from being an arm of public administration into an economically independent and responsible entity. Whilst the overall rating of the hospital remained constant over time, there was variation between disease patient groups (see Figure 2, panel b) and between organisational units of the hospital (see Figure 2, panel c). Satisfaction scores were also found to be influenced by the category of patient admission (emergency versus elective, data not shown), the type of insurance (private $v s$. general, panel d) as well as patient gender (panel e), patient origin (panel f) and age (not shown), whereas the length of stay was without influence (data not shown). These differences masked each other and were no longer visible at the level of the entire hospital (see Figure 2, panel a).

Five major components influencing patient satisfaction were interpreted from factorial analysis using a Screeplot including "elbow criteria" (see Figure 3) with the 6th component exhibiting no relevant increase in explained variance. The results were the same independent of whether this factorial analysis was performed on the entire sample, for each individual year of the study, or for subgroups within the hospital. The variance explained by the five factors was $56.5 \%$. The structure of these five components (see Table 2) was: (1) Partnership between patients and health care professionals was a component summarising the results of six questions pertaining to the coherence of provided information, involvement in decision-making and treatment with dignity and respect. (2) Responsiveness was a component integrating three questions pertaining to the availability and the ability of health care personnel to take care of concerns and anxiety of patients. (3) Information integrated three questions addressing effects and potential side effects of the medica- 
tion and the warning signals to be observed after discharge from the hospital. (4) Family involvement was a component composed of two questions exploring the quality of information provided to families and relatives of the patient.
(5) Pain control was a single question-based component that directly reflected the perceived quality of the pain service (if applicable).

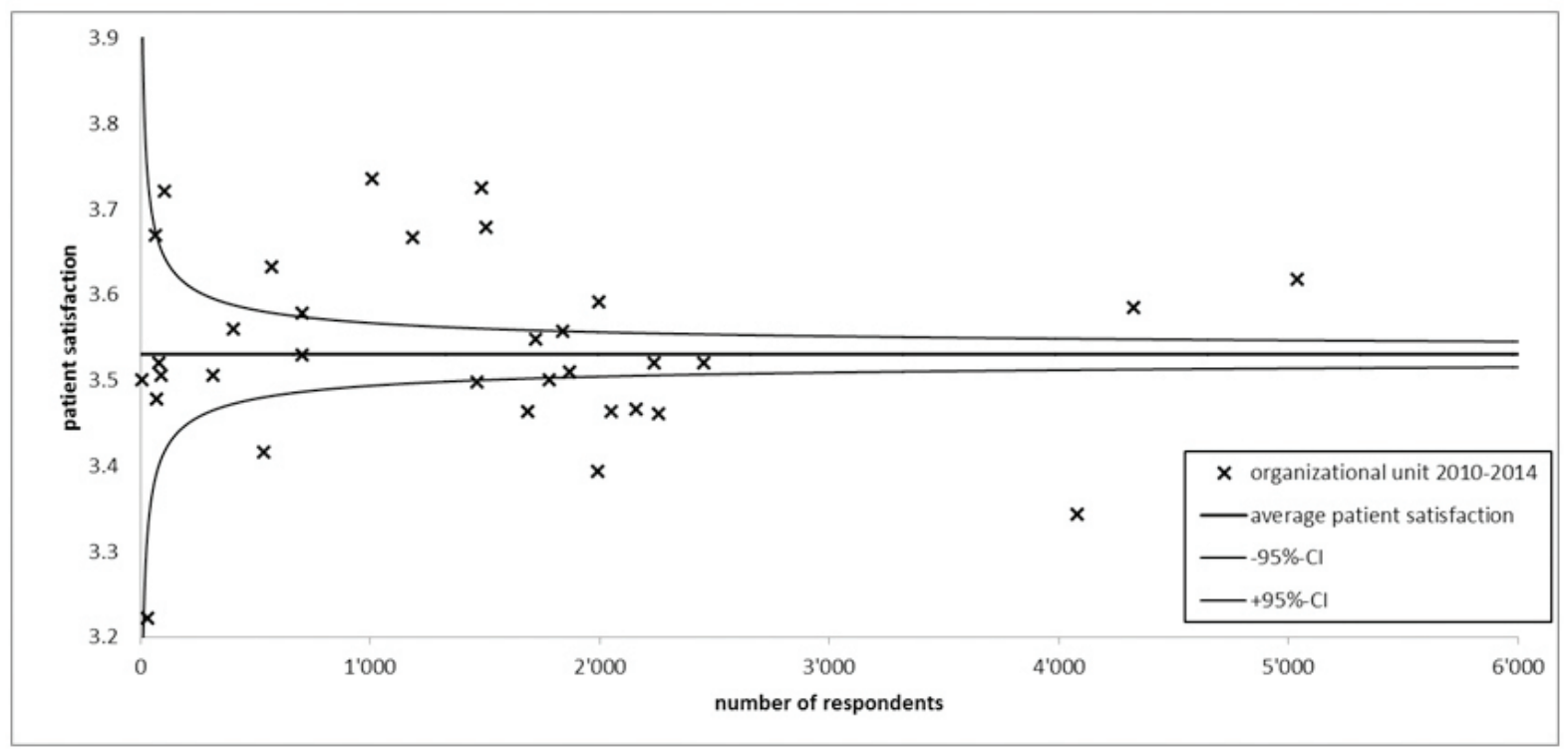

Figure 1. Variation of patient satisfaction among organisational units (wards)

Each point represents a specific unit (ward) of the hospital, for which average patient satisfaction for the observational period 2010-14 (ordinate) and the respective number of respondents (abscissa) are indicated. The confidence interval is calculated based on the average standard deviation of the total sample $(=0.59)$ and the number of respondents (abscissa) for $p=.05$.

Variance analysis testing of all components (including the 5 components as covariates) showed that $36 \%$ of variance can be explained whereas patient-related variables (age, gender, origin, admission status, length of stay etc.) and an organisational variable (ward) were much less important than the five components. Component 1 (Partnership) was predominant, explaining 25.2\% (see Table 3, Partial Eta Squared) of the variance. This variance analysis showed that all five components had an impact on patient satisfaction with the comparative relevance of Partnership (25.2\%) > Information $(7.6 \%)>$ Responsiveness $(3 \%)>$ Family involvement $(2.8 \%)$ $>$ Pain control (1.3\%) (see Table 3, Partial Eta Squared).

Among the single factors, organisational units $(0.7 \%)$, age $(0.22 \%)$, patient origin $(0.12 \%)$ and gender $(0.1 \%)$ had the greatest explanatory power but none of these factors attained $1 \%$ variance. There was no significant influence $(p>.05)$ of admission status, disease severity or length of stay on patient satisfaction.

\section{Discussion}

Today, patients are no longer viewed as the subjects of healthcare but as clients who make choices and as co-producers, who provide information, participate in decision-making, monitor medication and play an active role in the treatment

Published by Sciedu Press process. ${ }^{[22,23]}$ As a consequence, the judgement of patients has received a great deal of attention both in healthcare management and in research: measures ${ }^{[24]}$ and scales ${ }^{[17]}$ have been debated, dimensions of patient experience ${ }^{[25]}$ and components that determine patient satisfaction have been researched over the years. ${ }^{[26]}$ As a result, a large number of validated instruments are available allowing the measurement of patient experience and satisfaction. In this study the use of a funnel plot visualisation of patient subgroups enabled quickly the differentiation of outliers and is proposed as a useful tool to detect differences within a hospital.

A number of authors have shown the importance of staffpatient communication and involvement. This study, explaining an average $36 \%$ patient satisfaction variance is mid-range when compared to the literature $8 \%-23 \%,{ }^{[27]}$ a study revealing a time component with $26 \%$ immediately and $40 \%$ at 3 months, ${ }^{[28]} 59 \%$ in a Norwegian study ${ }^{[29]}$ up to $97 \% .{ }^{[30]}$ The $97 \%$ variance accounted for in the latter study represents a highly homogeneous patient population and is unlikely to be representative for entire hospital patient samples. Since one important application of the findings is to compare performance between hospitals, we decided to remain with the broad, hospital-level approach. 
panel a

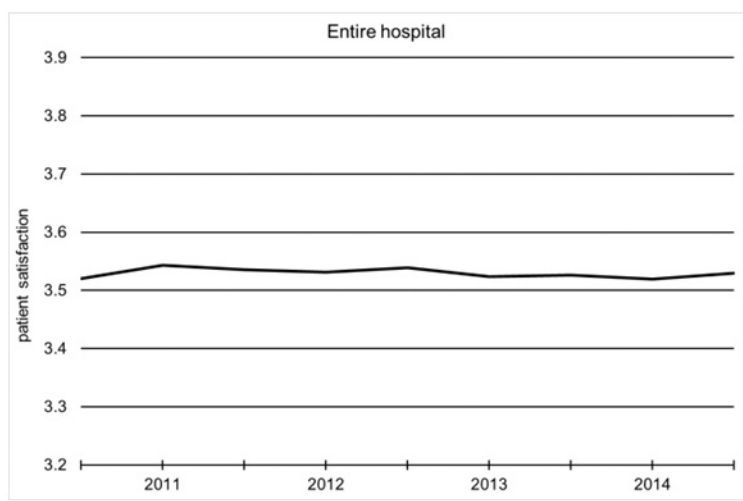

panelc

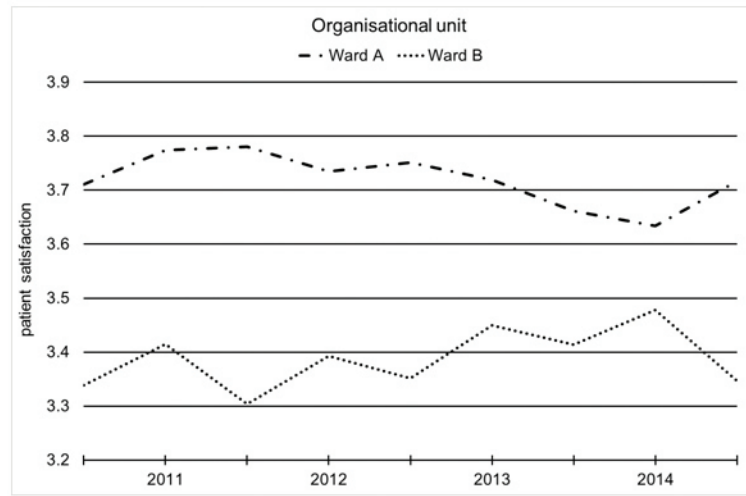

panel e

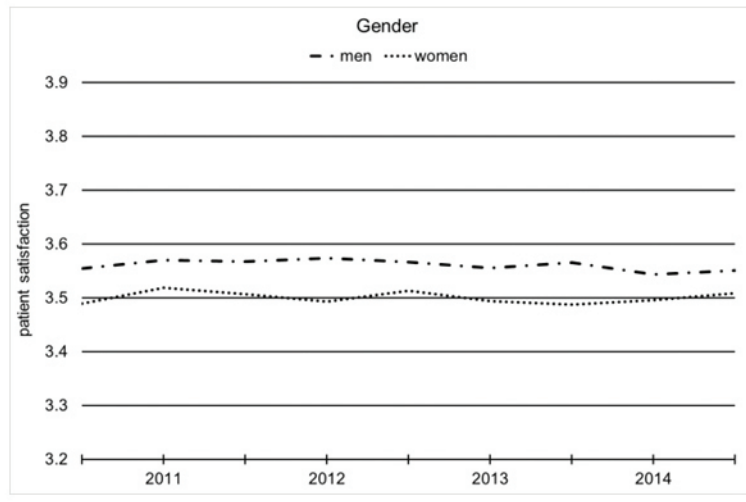

panel b

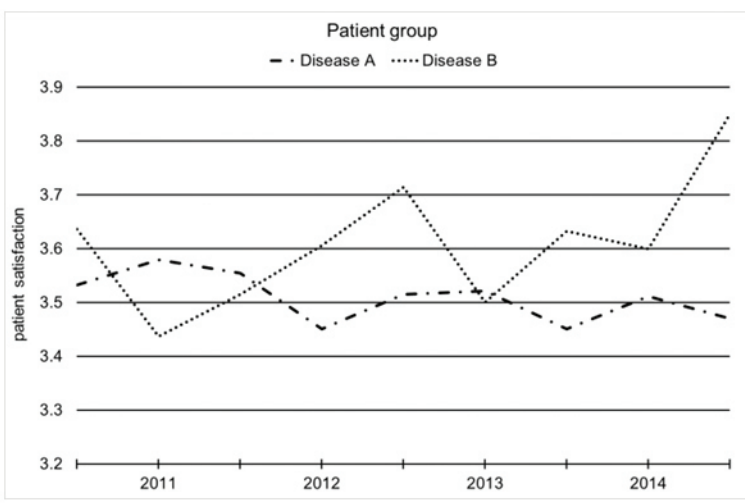

paneld

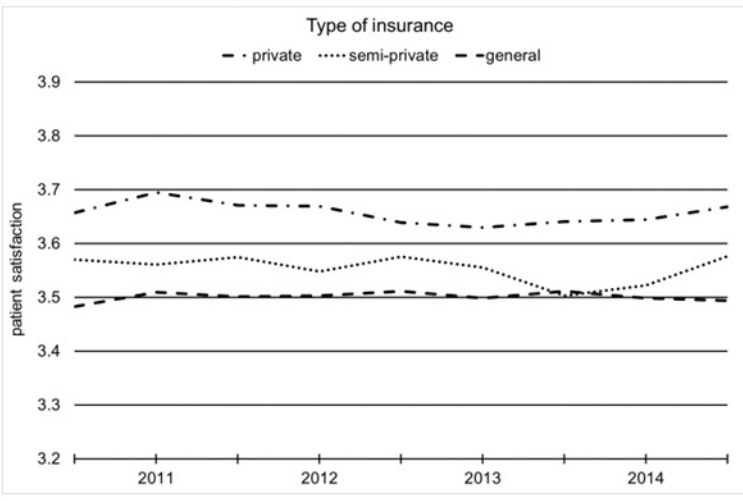

panelf

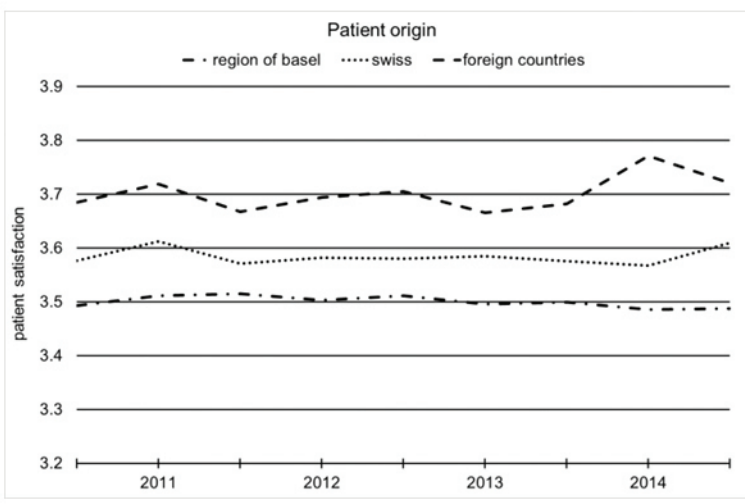

Figure 2. Variation of patient satisfaction over periods of time (a) for the hospital as an entity, (b) for two examples of disease-defined patient groups (pneumonia and hysterectomy for benign disease), (c) for two examples of organisational units (wards), (d) for patients with different types of insurances, (e) according to gender and (f) according to patient origin (place of domicile). Points indicate the mean of the respective sample for each half year period.

Heterogeneity of patient satisfaction within one and the same hospital results from organisational units and patient groups reporting high ratings of patient satisfaction which co-exist with others that report low satisfaction rates. Furthermore, opposite trends over time were observed where satisfaction is improved in some but deteriorates in others. Positive and negative trends hedged each other, resulting in no change of overall patient satisfaction during the period of observation, in spite of significant environmental changes. During the time of this study both the reimbursement systems changed in the hospital as well as the hospital status by becoming independent in 2013, neither of these important changes was 
reflected by changes in patient satisfaction.

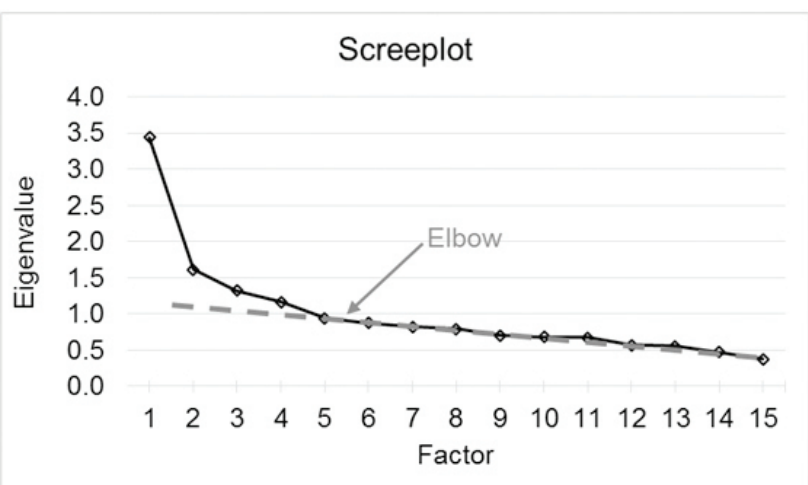

Figure 3. Factorial analysis following dichotomisation of the variables Q1 to Q16, without Q10 suggests a five component structure by Screeplot

Within the stable overall picture of hospital satisfaction exists a heterogeneity derived from differences between organisational groups, patient health status and different patient disease groups, amongst others. The observation confirms our starting hypothesis of heterogeneity in a hospital. The difference between wards has been reported previously ${ }^{[15]}$ and patients with chronic illnesses ${ }^{[31,32]}$ have reported lower scoring feedbacks whereas those with better health and function ${ }^{[33,34]}$ provided higher score feedbacks. As described in Crow $^{[35]}$ (including Table 19 covering 31 studies), the literature results are somewhat equivocal, but generally sicker patients, with a poorer physical status, were seen to record lower satisfaction. In our study we observed a difference between organisational units and between patient disease groups.

Whether a patient volunteered for treatment (elective), or it is obligatory (emergency), also influences their satisfaction level. In UHB elective admission patients responded with higher levels of satisfaction than emergency patients, which has also been observed in the literature. ${ }^{[17,36]}$ In this study privately insured patients provided higher satisfaction ratings than general patients.

Table 2. Identification of five components using rotated component matrix (only factor loadings $>0.4$ are shown)

\begin{tabular}{|c|c|c|c|c|c|}
\hline & \multicolumn{5}{|c|}{ Component (Factor) } \\
\hline & C1 & C2 & C3 & C4 & C5 \\
\hline Q7 Did you feel like you were treated with respect and dignity while you were in the hospital? & 0.64 & & & & \\
\hline Q2 When you had important questions to ask a doctor, did you get answers you could understand? & 0.63 & & & & \\
\hline Q1 When you had important questions to ask a nurse, did you get answers you could understand? & 0.61 & & & & \\
\hline Q5 Did the doctors talk in front of you as if you weren't there? & 0.57 & & & & \\
\hline $\begin{array}{l}\text { Q3 Sometimes in the hospital, one doctor or nurse will say one thing and another will say something quite } \\
\text { different. Did it happen to you? }\end{array}$ & 0.55 & & & & \\
\hline Q6 Did you have enough to say about your treatment? & 0.45 & & & & \\
\hline Q8 If you had any anxieties or fears regarding your condition or treatment, did a nurse discuss them with you? & & 0.82 & & & \\
\hline Q4 If you had any anxieties or fears about your condition or treatment, did a doctor discuss them with you? & & 0.77 & & & \\
\hline Q9 Was it easy for you to find someone on the hospital staff to talk to regarding your concerns? & & 0.62 & & & \\
\hline Q15 Did someone tell you about the medication side effects to watch out for after you went home? & & & 0.79 & & \\
\hline $\begin{array}{l}\text { Q14 Did someone on the hospital staff explain the purpose of the medicine you were to take at home in a way } \\
\text { you could understand? }\end{array}$ & & & 0.74 & & \\
\hline $\begin{array}{l}\text { Q16 Were you informed about possible danger signals for your illness, or from operation, which you should } \\
\text { watch out for at home? }\end{array}$ & & & 0.63 & & \\
\hline Q12 Did your family, or someone close to you, have enough opportunity to talk to your doctor? & & & & 0.88 & \\
\hline $\begin{array}{l}\text { Q13 Did the doctors and nurses give your family, or someone close to you, all the information they needed to } \\
\text { help you recover? }\end{array}$ & & & & 0.86 & \\
\hline Q11 Do you think that the hospital staff did everything they could to help control pain? & & & & & 0.95 \\
\hline
\end{tabular}

Note. The 5 components from the Screeplot (see Figure 3) identified using a rotated component matrix. Based on the contributing factors structure the components are termed C1 partnership, C2 responsiveness, C3 information, C4 family involvement and C5 pain control.

In a review of 39 studies in the literature ${ }^{[35]}$ there was no consensus regarding a correlation between patient gender and level of satisfaction. $15 \%$ of the studies showed that women were more satisfied, $18 \%$ showed men to be more

Published by Sciedu Press satisfied and $67 \%$ of the studies showed no significant gender difference. In contrast, in our study women throughout the time period consistently were less satisfied than males (see Figure 2 panel e). 
Foreigners to Switzerland provided higher satisfaction feed- nationality effect is probably influenced by the fact that in back than Swiss patients, who exceeded the ratings of local patients (Basel inhabitants, see Figure 2 panel f). The patient our sample the majority of foreign patients also happened to be privately insured.

Table 3. Variance analysis with patient satisfaction as the dependent variable

\begin{tabular}{lllllll}
\hline Source & Type III Sum of Squares & df & Mean Square & F & Sig. & Partial Eta Squared \\
\hline Corrected Model & $6726.216 \mathrm{a}$ & 60 & 110.266 & 487.687 & .000 & 0.3571 \\
Intercept & 329.436 & 1 & 329.436 & 1457.041 & .000 & 0.0265 \\
Patient origin & 14.239 & 2 & 7.119 & 31.488 & .000 & 0.0012 \\
Migration status & 3.136 & 1 & 3.136 & 13.868 & .000 & 0.0003 \\
Age & 26.254 & 10 & 2.625 & 11.612 & .000 & 0.0022 \\
Gender & 11.780 & 1 & 11.780 & 52.100 & .000 & 0.0010 \\
Admission status & .278 & 2 & .139 & .614 & .541 & 0.0000 \\
Type of insurance & 4.886 & 2 & 2.443 & 10.805 & .000 & 0.0004 \\
Organisational units & 85.574 & 32 & 2.674 & 11.827 & .000 & 0.0070 \\
Destination & 2.107 & 2 & 1.053 & 4.659 & .009 & 0.0002 \\
Comorbidity & .956 & 3 & .319 & 1.409 & .238 & 0.0001 \\
Length of stay & .013 & 1 & .013 & .059 & .808 & 0.0000 \\
Covariates: & & & & & & \\
C1 Partnership & 4076.316 & 1 & 4076.316 & 18028.853 & .000 & 0.2519 \\
C2 Responsiveness & 370.232 & 1 & 370.232 & 1637.475 & .000 & 0.0297 \\
C3 Information & 991.069 & 1 & 991.069 & 4383.329 & .000 & 0.0757 \\
C4 Family involvement & 348.108 & 1 & 348.108 & 1539.620 & .000 & 0.0280 \\
C5 Pain control & 157.898 & 1 & 157.898 & 698.355 & .000 & 0.0129 \\
\hline
\end{tabular}

Note. $\mathrm{R}$ Squared $=0.357$ (Adjusted R Squared $=0.356$ ), Admission status (emergency-elective), comorbidity (Charlson index) and length of stay (days) do not significantly correlate with patient satisfaction ( $p>.05$ see significance column). The converted part, which explains the independent factors in the patient satisfaction variance, can be seen in the column "partial Eta squared" ( $0=0 \%$ explained variance, $1=100 \%$ explained variance $)$.

In our case patients' age influenced feedback (see Table 3, $0.22 \%$ variance), albeit with a low level of influence whereas in the literature the data is more equivocal with some saying that neither age, gender nor length of stay explained the variation in patient satisfaction ${ }^{[30,37]}$ and others claiming age codetermines patient satisfaction. ${ }^{[38,39]}$ The majority of authors do however agree that older patients (e.g. $>65$ years) provide higher satisfaction scorings; ${ }^{[28,35]}$ but the correlation is reduced when multivariate analysis is performed. ${ }^{[26]}$

In a Dutch hospital study ${ }^{[40]}$ comparing the length of stay with patient satisfaction, no clear relationship could be found in the majority of wards. It was expected that a shorter stay correlated with better quality of care, less adverse side effects and leading to improved patient satisfaction, but this was not observed. This was confirmed by other authors and in this study (data not shown).

There is no doubt that the composition of the questionnaire determines the range of components. It is also possible that components codetermining patient satisfaction (such as attainment of expectations) are missing. Further, the some- times contradictory results reported in the literature may result from different definitions of patient satisfaction. Whilst our data confirm the relevance of many socio-demographic factors, the impact of these variables was orders of magnitude lower than the impact of patient-staff interactions or "partnership". Others have also reported that they are minor predictors of patient satisfaction. ${ }^{[41]}$ These factors may nevertheless serve to differentiate hospitals and provide competitive advantages. We were surprised by the magnitude that the factor "partnership" outperformed the other components. Furthermore, this factor predominated independent of organisational- or patient-groups, as well as over time. This observation not only confirms concepts of patient empowerment and coproduction but also provides leverage to improve patient satisfaction. Patient centredness and empathy during consultations has been shown already in 1998 by Williams et $a l .{ }^{[42]}$ to be associated with increased patient satisfaction and that the physician-patient communication has the strongest impact on patient satisfaction. ${ }^{[33]}$

The quality of information provided to the patient on dis- 
charge (description of medication, drug side effects and disease-related dangers to watch out for) accounted for $7.6 \%$ of patient satisfaction variance. This was less critical than staff-patient interactions during hospital stay, but more important than all other remaining tested variables taken together and is clearly an area where easily implementable improvements can be made. A study of German hospitals ${ }^{[26]}$ also found a small correlation between patient satisfaction and discharge procedure and instructions.

Finally, even though more sophisticated measurements of patient satisfaction are evolving with time, they are meaningless without an implementation plan based on the findings. Clinicians have been reported to often ignore survey results. ${ }^{[44,45]}$ In a survey of four hospitals (in Denmark, Israel, UK \& USA) $90 \%$ clinicians thought improving patient satisfaction was achievable, but only $9 \%$ had a structured plan to do so. Additionally, only $34 \%$ received feedback from hospital management on their departments' performance. ${ }^{[46]}$ Whilst patient-centred care is thought important, the majority do not have an improvement plan which engages clinicians. ${ }^{[46,47]}$ This should be addressed in parallel to identifying areas for improvement and monitoring patient satisfaction.

\section{Limitations of the study}

The study was performed over a comparably long period of time and recruited a large number of patients. However, it remains a single center study where a comparison of responders and non-responders was not performed, thus generalisation of the data should be performed with caution.

Non-respondents are likely to include severely ill and elderly (likely to provide more positive responses) as well as cognitively impaired and immigrant patients with language difficulties. We used multi-language questionnaires covering the most represented 6 languages in order to control this effect.

Possible respondent biases could derive from (1) socially desirable responses (minimised by the respect of anonymity in our study), (2) cognitive consistency pressure in the event of continuing use of the hospitals services, (3) acquiescent response bias, or tendency to respond positively. These features are common to most patient satisfaction questionnaires.
The use of an alternative data collection method (such as personal interviews) would provide a useful cross-check of the findings.

The focus of the questionnaire excludes hotel business, infrastructure etc. where a key influence of the service factors such as food quality and accommodation have been shown. ${ }^{[26]}$ This questionnaire was developed as a basis for the current national Swiss core questionnaire and then used for a different purpose. However, the large data source used in this study compensates for any deficiency.

Finally, the response scale of the questionnaire was found to be neither ideal for the analysis of variance performed in this study, nor for measurement sensitivity (ceiling effect). This has been analysed, tested and described in a different paper and needs to be improved in the future. ${ }^{[17]}$

\section{Conclusions}

This study confirms the value of the voice of the patient. The relationship between active patient involvement and their level of satisfaction is consistent. The heterogeneous structure of the hospital with its many overlay structures requires a differentiated analysis for appropriately defined subunits and the comparison over periods of time in order to detect fine differences, such as socio-demographic influences, in patient feedback.

We propose analysis tools such as the funnel plot for rapid visualisation of results and outliers that require further analysis. Such detailed analysis probably provides a sound basis for quality initiatives and their monitoring, whereas reports at the hospital level may obscure relevant trends.

Partnership between patients and health care professionals was confirmed to be a key determinant of patient satisfaction accounting for considerably more patient satisfaction than all other monitored components. This is neither a surprise nor counterintuitive. Still, this concept remains far from universal acceptance and daily practice. Our data emphasises this factor and therefore hopefully contributes to improving patient care, patient satisfaction and outcome of health care. If the patient is accepted as a co-producer in health care, then we should listen to and make use of his voice.

\section{REFERENCES}

[1] Price RA, Elliott MN, Zaslavsky AM, et al. Examining the role of patient experience surveys in measuring health care quality. Medical Care Research and Review. 2014; 71(5): 522-554. http: //dx.doi.org/10.1177/1077558714541480

Published by Sciedu Press
[2] Goldstein E, Cleary PD, Langwell KM, et al. Medicare managed care CAHPS ${ }^{\circledR}$ : A tool for performance improvement. Health Care Financing Review. 2001; 22(3): 101-107. PMID:25372460.

[3] Jenkinson C, Coulter A, Bruster S. The picker patient experience questionnaire: Development and validation using data from in-patient 
surveys in five countries. International Journal for Quality in Health Care. 2002; 14(5): 353-358. http://dx.doi.org/10.1093/int qhc/14.5.353

[4] Elliott MN, Lehrman WG, Goldstein E, et al. Do hospitals rank differently on HCAHPS for different patient subgroups? Medical Care Research and Review. 2009. http://dx.doi.org/10.1177/107 7558709339066

[5] Bell R, Krivich MJ, Boyd MS. Charting patient satisfaction. Marketing health services. 1997; 17(2): 22-29. PMID:10170284.

[6] Brédart A, Bottomley A. Treatment satisfaction as an outcome measure in cancer clinical treatment trials. 2002; 2(6): 597-606. http://dx.doi.org/10.1586/14737167.2.6.597

[7] Emanuel EJ, Emanuel LL. Four models of the physician-patient relationship. Jama. 1992; 267(16): 2221-2226. http://dx.doi .org /10.1001/jama.1992.03480160079038

[8] Smith SK, Dixon A, Trevena L, et al. Exploring patient involvement in healthcare decision making across different education and functional health literacy groups. Social science \& medicine. 2009; 69(12): 1805-1812. http://dx.doi.org/10.1016/j.socscim ed.2009.09.056

[9] Chewning B, Bylund CL, Shah B, et al. Patient preferences for shared decisions: A systematic review. Patient education and counseling. 2012; 86(1): 9-18. http://dx.doi.org/10.1016/j.pec. 2011 02.004

[10] Richards T, Montori VM, Godlee F, et al. Let the patient revolution begin. BMJ. 2013; 346: f2614. http://dx.doi.org/10.1136/b $\mathrm{mj} . \mathrm{f} 2614$

[11] Aiken LH, Sermeus W, Van den Heede K, et al. Patient safety, satisfaction, and quality of hospital care: Cross sectional surveys of nurses and patients in 12 countries in Europe and the United States. BMJ. 2012; 344: e1717. http://dx.doi.org/10.1136/bmj .e1717

[12] Wright JD, Tergas AI, Ananth CV, et al. Relationship between surgical oncologic outcomes and publically reported hospital quality and satisfaction measures. J Natl Cancer Inst. 2015; 107(3): dju 409. http://dx.doi.org/10.1093/jnci/dju409

[13] Mpinga EK, Chastonay P. Patient satisfaction studies and the monitoring of the right to health: Some thoughts based on a review of the literature. Global Journal of Health Science. 2011; 3(1): 64-69. http://dx.doi.org/10.5539/gjhs.v3n1p64

[14] Mintzberg H. Toward healthier hospitals. Health Care Management Review. 1997; 22(4): 9-18. http://dx.doi.org/10.1097/000 04010-199710000-00005

[15] Ancarani A, Di Mauro C, Giammanco MD. How are organisational climate models and patient satisfaction related? A competing value framework approach. Social science \& medicine. 2009; 69(12): 1813-1818. http://dx.doi.org/10.1016/j.socscim ed.2009.09.033

[16] Keller AC, Bergman MM, Heinzmann C, et al. The relationship between hospital patients' ratings of quality of care and communication. International journal for quality in health care. 2014; 26(1): 26-33. http://dx.doi.org/10.1093/intqhc/mzt083

[17] Dell-Kuster S, Sanjuan E, Todorov A, et al. Designing questionnaires: healthcare survey to compare two different response scales. BMC medical research methodology. 2014; 14(1): 96. http://dx.doi.o $\mathrm{rg} / 10.1186 / 1471-2288-14-96$

[18] Bortz J, Döring N. Forschungsmethoden und Evaluation für Humanund Sozialwissenschaftler. Limitierte Sonderausgabe: SpringerVerlag; 2007.

[19] Backhaus K, Erichson B, Plinke W, et al. Multivariate Analysemethoden: Eine anwendungsorientierte Einführung. Berlin: Springer; 2013. http://dx.doi.org/10.1007/978-3-662-08893-7
[20] Garratt AM, Helgeland J, Gulbrandsen P. Five-point scales outperform 10-point scales in a randomized comparison of item scaling for the Patient Experiences Questionnaire. Journal of clinical epidemiology. 2011; 64(2): 200-207. http://dx.doi.org/10.1016/j.j clinepi.2010.02.016

[21] Moret L, Nguyen J-M, Pillet N, et al. Improvement of psychometric properties of a scale measuring inpatient satisfaction with care: a better response rate and a reduction of the ceiling effect. BMC health services research. 2007; 7(1): 197. http://dx.doi.org/10.1186 /1472-6963-7-197

[22] Hipp R, Prengel A, Nebl T, et al. Der Patient als Kunde-Chancen und Risiken einer neuen Positionierung für den Patienten im Krankenhaus. Dtsch Med Wochenschr. 2010; 135: 251-255. http://dx.d oi.org/10.1055/s-0030-1247863

[23] Porter ME, Teisberg EO. Redefining health care: creating valuebased competition on results. Boston, MA: Harvard Business Press; 2006.

[24] Ross CK, Steward CA, Sinacore JM. A comparative study of seven measures of patient satisfaction. Medical care. 1995; 33(4): 392-406. http://dx.doi.org/10.1097/00005650-199504000-00006

[25] Stahl K, Lietz D, Riechmann M, et al. Patientenerfahrungen in der Krankenhausversorgung: Revalidierung eines Erhebungsinstruments Revalidation of a questionnaire assessing patients' experiences in hospital. Zeitschrift für Medizinische Psychologie. 2012; 21(1): 1120.

[26] Schoenfelder T, Klewer J, Kugler J. Determinants of patient satisfaction: a study among 39 hospitals in an in-patient setting in Germany. International journal for quality in health care. 2011; 23(5): 503-509. http://dx.doi.org/10.1093/intqhc/mzr038

[27] Rademakers J, Delnoij D, de Boer D. Structure, process or outcome: which contributes most to patients' overall assessment of healthcare quality? BMJ quality \& safety. 2011: bmjqs. 2010.042358 http://dx.doi.org/10.1136/bmjqs . 2010.042358

[28] Jackson JL, Chamberlin J, Kroenke K. Predictors of patient satisfaction. Social science \& medicine. 2001; 52(4): 609-620. http: //dx.doi.org/10.1016/S0277-9536(00) 00164-7

[29] Bjertnaes OA, Sjetne IS, Iversen HH. Overall patient satisfaction with hospitals: effects of patient-reported experiences and fulfilment of expectations. BMJ quality \& safety. 2012; 21(1): 39-46. http://dx.doi.org/10.1136/bmjqs-2011-000137

[30] Hamilton D, Lane JV, Gaston P, et al. What determines patient satisfaction with surgery? A prospective cohort study of 4709 patients following total joint replacement. BMJ Open. 2013; 3(4): e002525. http://dx.doi.org/10.1136/bmjopen-2012-002525

[31] Zapka JG, Palmer RH, Hargraves JL, et al. Relationships of patient satisfaction with experience of system performance and health status. The journal of ambulatory care management. 1995; 18(1): 73-83. http://dx.doi.org/10.1097/00004479-199501000-00008

[32] Deale A, Wessely S. Patients' perceptions of medical care in chronic fatigue syndrome. Social science \& medicine. 2001; 52(12): 1859-1864. http://dx.doi.org/10.1016/S0277-953 6(00) 00302-6

[33] Nguyen TD, Attkisson CC, Stegner BL. Assessment of patient satisfaction: development and refinement of a service evaluation questionnaire. Evaluation and program planning. 1983; 6(3): 299-313. http://dx.doi.org/10.1016/0149-7189(83)90010-1

[34] Rahmqvist M. Patient satisfaction in relation to age, health status and other background factors: a model for comparisons of care units. International Journal for Quality in Health Care. 2001; 13(5): 385-390. http://dx.doi.org/10.1093/intqhc/13.5.385 
[35] Crow R, Gage H, Hampson S, et al. The measurement of satisfaction with healthcare: implications for practice from a systematic review of the literature. Health Technol Assess. 2002; 6(32): 1-244.

[36] Williams G, Pattison G, Mariathas C, et al. Improving parental satisfaction in pediatric orthopaedics. Journal of Pediatric Orthopaedics. 2011; 31(5): 610-615. http://dx.doi.org/10.1097/BPO.0b0 $13 e 3182203955$

[37] González N, Quintana JM, Bilbao A, et al. Development and validation of an in-patient satisfaction questionnaire. International Journal for Quality in Health Care. 2005; 17(6): 465-472. http: //dx.doi.org/10.1093/intqhc/mzi067

[38] Schoenfelder T, Klewer J, Kugler J. Factors associated with patient satisfaction in surgery: the role of patients' perceptions of received care, visit characteristics, and demographic variables. Journal of Surgical Research. 2010; 164(1): e53-e59. http://dx.doi.org/10. 1093/intqhc/mzr038

[39] Jaipaul CK, Rosenthal GE. Are older patients more satisfied with hospital care than younger patients? Journal of general internal medicine. 2003; 18(1): 23-30. http://dx.doi .org/10.1046/j.1525-149 7.2003.20114.x

[40] Borghans I, Kleefstra SM, Kool RB, et al. Is the length of stay in hospital correlated with patient satisfaction? International Journal for Quality in Health Care. 2012; 24(5): 443-451. http://dx.doi.o rg/10.1093/intqhc/mzs037

[41] Hall JA, Dornan MC. Patient sociodemographic characteristics as predictors of satisfaction with medical care: a meta-analysis. Social science \& medicine. 1990; 30(7): 811-818. http://dx.doi.org /10.1016/0277-9536(90) 90205-7

[42] Williams S, Weinman J, Dale J. Doctor-patient communication and patient satisfaction: a review. Family Practice. 1998; 15(5): 480-492. http://dx.doi.org/10.1093/fampra/15.5.480

[43] Anderson R, Barbara A, Feldman S. What patients want: A content analysis of key qualities that influence patient satisfaction. J Med Pract Manage. 2007; 22(5): 255-261. PMID:17494478.

[44] Cheraghi-Sohi S, Bower P. Can the feedback of patient assessments, brief training, or their combination, improve the interpersonal skills of primary care physicians? A systematic review. BMC Health Services Research. 2008; 8(1): 179. http://dx.doi.org/10.1186 /1472-6963-8-179

[45] Reinders ME, Ryan BL, Blankenstein AH, et al. The effect of patient feedback on physicians' consultation skills: a systematic review. Academic Medicine. 2011; 86(11): 1426-1436. http://dx.doi.o $\mathrm{rg} / 10.1097 / \mathrm{ACM}$. Ob013e3182312162

[46] Rozenblum R, Lisby M, Hockey PM, et al. The patient satisfaction chasm: the gap between hospital management and frontline clinicians. BMJ quality \& safety. 2012: bmjqs-2012-001045. http://dx.doi.org/10.1136/bmjqs-2012-001045

[47] Coulter A, Locock L, Ziebland S, et al. Collecting data on patient experience is not enough: they must be used to improve care. BMJ 2014; 348: g2225. http://dx.doi.org/10.1136/bmj.g2225 